\title{
A NEW DEAD-WEIGHT TESTING MACHINE OF 100,000 POUNDS CAPACITY
}

\author{
By L. B. Tuckerman, Herbert L. Whittemore, and Serge N. Petrenko
}

\section{ABSTRACT}

The functions of the Bureau of Standards are outlined, and the importance of calibrating testing machines is emphasized.

The different methods of calibrating testing machines (A. S. T. M. specifications) are given, and the limitations of each are discussed.

The development of the proving ring is mentioned, and the need for apparatus for applying, preferably by dead weights, forces which are known accurately is brought out.

The dead-weight machine, capacity 100,000 pounds, which has been installed at the bureau is described and illustrated. Particular attention is given to the accuracy of the forces which can be applied by this machine and the precautions for maintaining the accuracy.

\section{CONTENTS}

I. Introduction

II. Thtroduction

II. Discussion of different methods of calibration

III. The 100,000-pound dead-weight machine

IV. Accuracy of the machine....... 263

V. Use of the machine

VI. Methods of calibration above 100,000 pounds

\section{INTRODUCTION}

The calibration of testing machines, for applying forces to specimens of engineering materials, is recognized as being an important function of the bureau and has received considerable attention as larger testing machines have been added to the equipment of the bureau. The use of dead weights for the calibration of testing machines involves serious disadvantages and is practically out of the question for horizontal testing machines. Accordingly, experiments were undertaken with apparatus which could be calibrated under accurately known forces and then used to measure the forces applied by testing machines. The requirements (1) that this calibrating apparatus should be portable, allowing it to be transported to the testing machine, and (2) that it should be accurate, made the development difficult and slow. A solution was finally found in the Whittemore-Petrenko proving ring.

Briefly, this instrument is a ring of heat-treated alloy steel to which forces may be applied along a diameter. The change in the diameter caused by the force is measured by a screw micrometer. A comparison of this device with other calibrating devices seems to show that the readings, on the average, are more accurate. It is also sufficiently rugged in construction to withstand field service. 


\section{DISCUSSION OF DIFFERENT METHODS OF CALIBRATION}

A procedure for calibrating testing machines is given in A. S. T. M. Standards, 1927, Part I, Metals, page 793, Standard Methods of Verification of Testing Machines, Serial Designation E 4-27.

It should be noted that-

"(A) Method of Verification by Standard Weights" is practicable only for testing machines of very small capacity; for example, 1,000 pounds.

"(B) Method of Verification by Standardized Proving Levers" is seldom used for forces above 10,000 pounds. At present this method is used only on vertical testing machines.

"(C) Method of Verification by Means of an Elastic Calibration Device" covers proving rings and similar devices. Elastic devices can be used for either horizontal or vertical machines. They have been used for forces up to $1,000,000$ pounds and appear to be the most practicable devices for calibrating large testing machines up to their capacity. The hydraulic support used by A. H. Emery in his precision-testing machines is the only, other portable device which appears to be suitable for this purpose. There are a number of testing machines in this country having a capacity of $1,000,000$ pounds or more and one at the Bureau of Standards having a capacity (in compression) of $10,000,000$ pounds.

"(D) Verification by Comparison Method," which consists in testing duplicate tensile specimens, some in the machine to be calibrated and some in a machine the errors in the load readings of which are known, is not sufficiently accurate to be satisfactory, especially, if the tolerances given in these A. S. T. M. standard methods are not to be exceeded.

\section{THE 100,000-POUND DEAD-WEIGHT MACHINE}

After the development of the proving ring, suitable for calibrating testing machines, it became necessary for the bureau to provide means for applying accurately known forces to these rings in order to determine their calibration constants. A dead-weight machine was, therefore, designed in cooperation with A. H. Emery, of Stamford, Conn., and built by Mr. Emery.

This machine was installed in November, 1927, and can be used to apply either tensile or compressive forces to elastic or other portable calibrating devices, by increments of 10,000 pounds, after an initial load of 2,000 pounds has been applied. The maximum force (or load) is 102,000 pounds.

This dead-weight machine is about 30 feet high and about 12 feet wide. The weights are on the first floor of the middle wing of the Industrial Building, the forces are applied to the calibrating device on the second floor, and a jack for lifting the weights is on the third floor. The machine is shown in Figures 1,2,3, and 4. The frame of the machine consists of two reinforced-concrete columns $A-A$ (figs. 1 and 2), extending from the concrete foundation at the base to the third floor where two steel I-beams $B-B$ (fig. 3), are placed across the tops of the columns. On these steel beams rests the hydraulic jack $C$ (fig. 3 ), which is operated by an electrically driven 
B. S. Journal of Research, RPI47

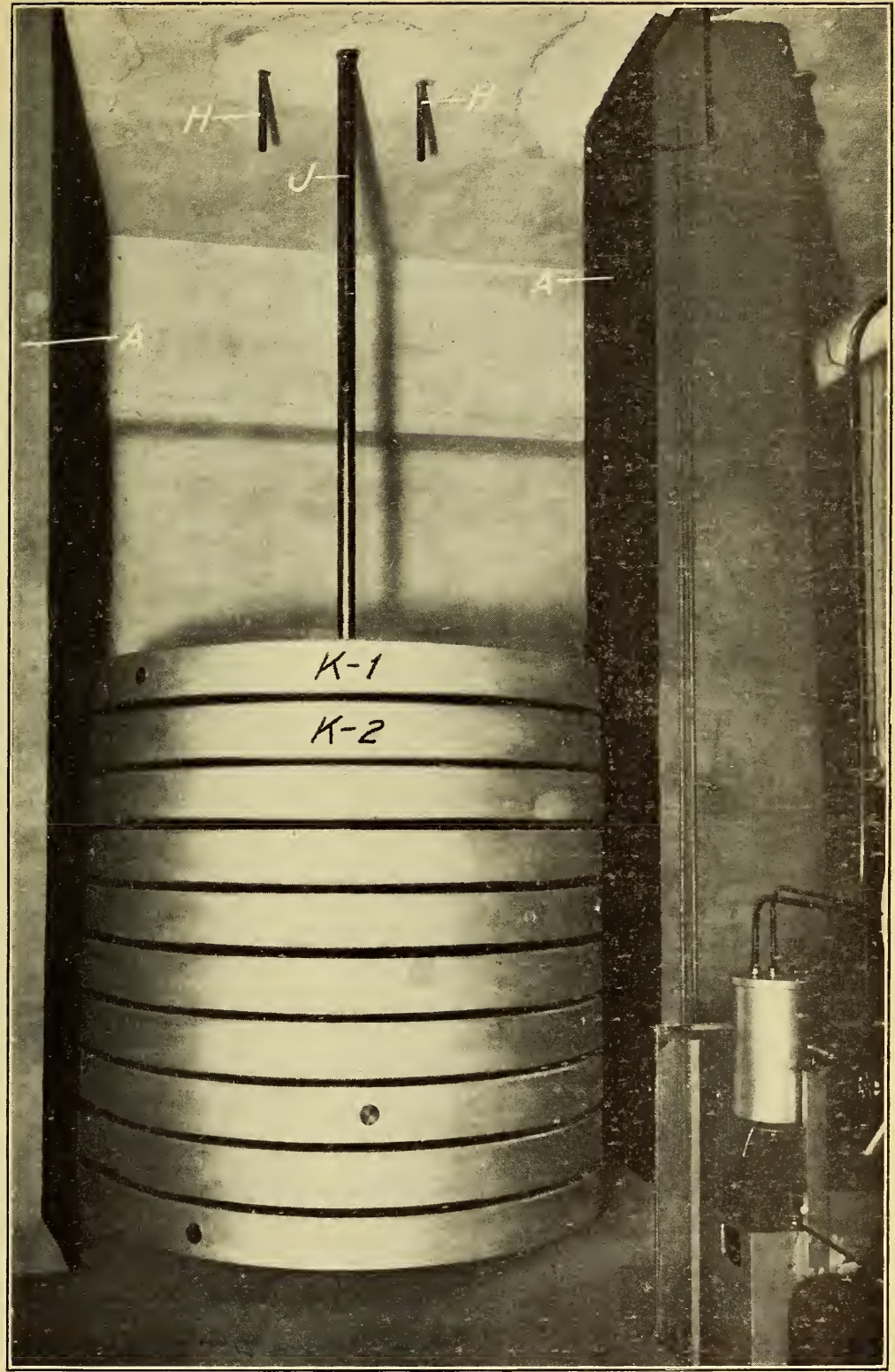

Figure 1.-Weights, 10,000 pounds each

As the loading bar, $J$ is raised about three-fourths of an inch, a head on the lower end of the bar engages a bevel seat in the axis of the top weight, $K-1$. On raising it farther, the other weights are raised in succession. 
B. S. Journal of Research, RP147

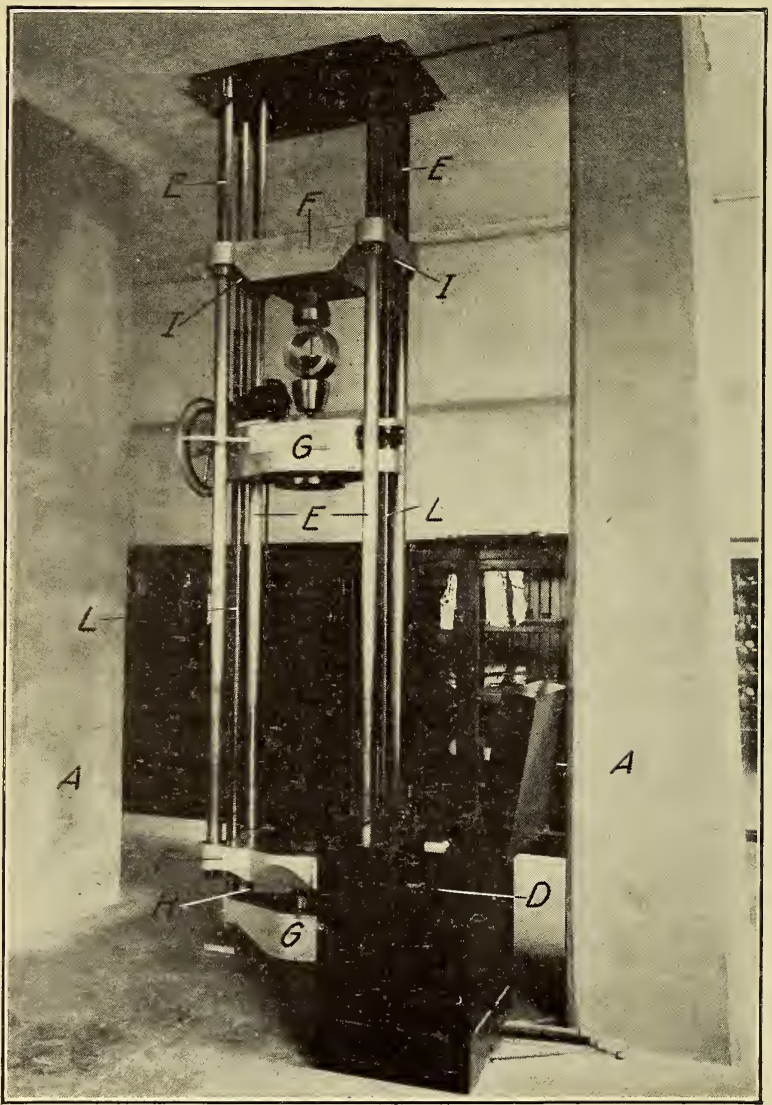

Figure 2.-Frames for loading the device to be calibrated

Upper frame, $E-E$ and $F-F$, is raised by the hydraulic jack on the floor above. The lower frame, $L-L$ and $G-G$, is connected to the weight on the floor below. A proving ring is shown between the upper and the lower frame, under a tensile force. 


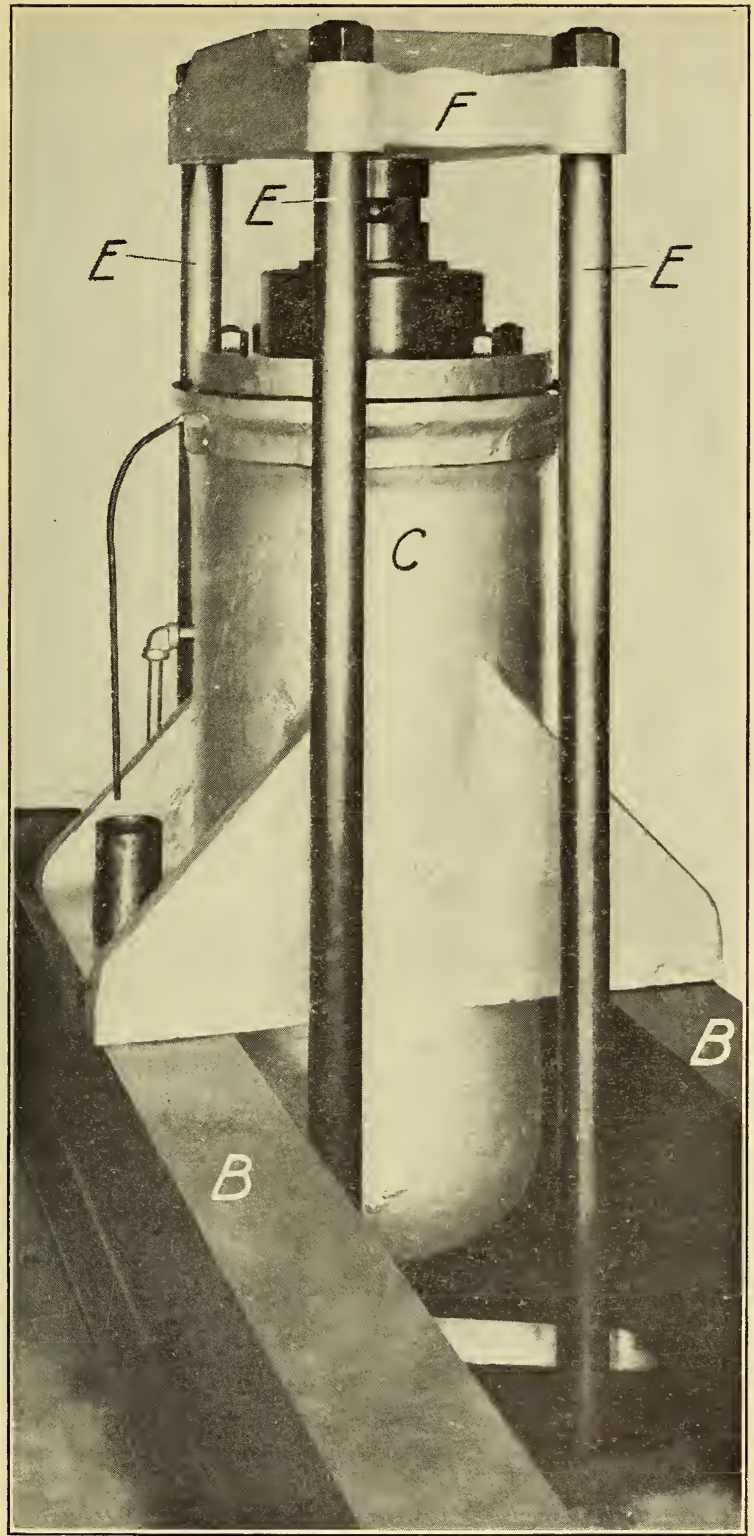

Figure 3.-The hydraulic jack for lifting the weights by means of the frames and the device to be calibrated

The yoke $F$ rests on a steel ball in the axis of the piston of the jack. 
B. S. Journal of Research, RPI47

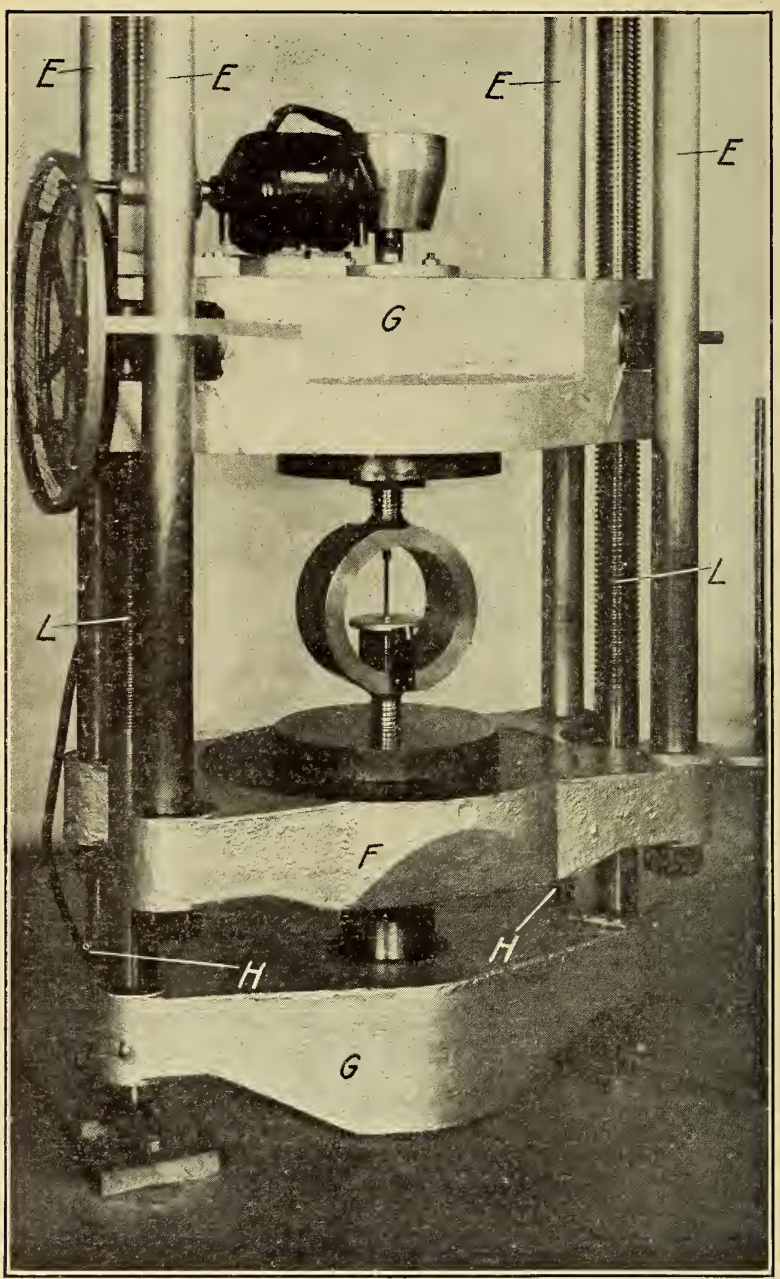

Figure 4.-Frames for loading the device to be calibrated. (See fig. 2)

A proving ring is shown under a compressive force. 
pump not shown. The control valves are in the case $D$ (fig. 2), on the second floor.

The apparatus for applying forces to the device to be calibrated consists of two frames. The upper frame (figs. $2,3,4$ ) consists of three yolzes $F$ connected by four rods $E$. The lower ends $H-H$ of two of these rods move in guides in the second floor. The top yoke $F$ (fig. 3) rests on a steel ball on the ram of the jack to insure axial loading. The lower frame (figs. 2 and 4 ) consists of two yokes $G$ connected by two rods $L$. These rods move vertically in guides $I-I$ (fig. 2), in the middle yoke of the upper frame. The upper yoke of the lower frame may be adjusted vertically on the threaded rods $L$ by rotating the nuts in the yoke by means of the electric motor and gearing shown in Figures 2 and 4 . This adjustment makes it possible to load proving rings or other calibrating devices in either tension or compression. The maximum distance between the loading yokes is about 6 feet 6 inches. To the lower yoke of the frame is suspended the loading bar $J$ (fig. 1) for lifting the weights $K-1, K-2$, etc. (fig. 1 ).

To apply forces to the calibrating device, the ram of the jack is raised, carrying the upper frame with it. The motion of the jack is transmitted to the lower frame through the proving ring or other calibrating device in the machine.

When the loading bar is raised about three-fourths of an inch a head on the lower end of this bar engages a bevel seat in the axis of the top weight $K-1$. On raising it further, a head on the top weight similar to the one on the loading bar engages the seat in the next weight $K-2$. On continuing to raise the loading bar, the other weights are suspended from it in succession until, when it is raised about 10 inches, all of the weights are suspended.

The weights are removed by lowering the jack. This action allows the bottom weight to come to rest on a bevel seat built into the foundation and each of the other weights in succession to rest on a similar seat on the weight below.

In Figure 2, a proving ring having a capacity of 100,000 pounds is shown in the dead-weight machine ready for the application of tensile forces. In Figure 4 the same ring is shown ready for the application of compressive forces.

The deformation of the proving ring, under the desired load, is measured by reading the micrometer.

\section{ACCURACY OF THE MACHINE}

Sleeves are provided in the guides $I$ for the lower frame. These sleeves can be rotated by hand to eliminate frictional forces on the rods $L$.

The weights are of cast iron and have a diameter of about 84 inches and a thickness of about 7.5 inches. Each one was carefully balanced. The center of gravity was in no case more than 0.018 inch from the geometrical center, the average being about 0.008 inch, and the weight was adjusted to 10,000 pounds by the division of weights and measures at the bureau before the machine was assembled. The maximum error in the weight of the lower frame (2,000 pounds) or of the cast-iron weights (10,000 pounds) was about 0.1 pound. 
Large cast-iron weights have been used in the railway test cars of the Bureau of Standards for calibrating track scales. These weights are transferred by a crane from the car to the scale and then reloaded into the car after the calibration. In service they are exposed to the weather.

Verification of these weights after they had been used for two years showed differences from the original weight, about 100,000 pounds, of as much as 5 pounds, which was sometimes a loss and sometimes a gain.

It is believed that no greater change in the weights for the deadweight machine is to be expected.

Great care was taken in assembling the machine to secure axial alignment of all the parts. After all the weights were placed in position on the bevel seat on the foundation, measurements showed that the center of the top weight was only about 0.06 inch from the vertical line of the machine and that its upper surface made an angle of about 28 minutes of arc with the horizontal.

Measurements on each weight after it was placed in position showed that its axis was nearer the center line and its upper surface more nearly horizontal than in the case of the top weight.

After the machine was assembled the jack which had been placed vertically above the center of the top weight was moved one-half the horizontal distance between the center of the bottom weight and the center of the top weight, or 0.03 inch, so that the maximum distance between the axis of any weight and the axis of the machine is now 0.03 inch.

To establish and maintain the vertical alignment of the machine a "reference plate" was built into the floor just below the jack. From a carefully located "center" in this plate a plumb line was suspended to fix the axis of the machine. This line can be replaced at any time to check the alignment of the machine, and adjustments, if necessary, can then be made.

\section{USE OF THE MACHINE}

The dead-weight machine is used not only for determining the calibration constants of proving rings and other devices for the bureau, but it is used also to calibrate similar devices for the public for which a nominal fee is charged.

\section{METHODS OF CALIBRATION ABOVE 100,000 POUNDS}

The problem of calibrating proving rings having capacities above 100,000 pounds has been given serious consideration. It does not appear practicable to build larger dead-weight machines; therefore, other methods will be studied in an endeavor to obtain satisfactory calibrations of proving rings which can be used for forces of $1,000,000$ pounds or more. This work is expensive and must necessarily await the provision of funds and personnel.

The bureau has in the past received many requests for calibrating testing machines in different parts of the country, but this calibration can not be undertaken without adequate provision for the apparatus, trained personnel, and traveling expenses.

Washington, May 13, 1929. 